\title{
Modification of wood with isopropyl glycidyl ether and its effects on decay resistance and light stability
}

\author{
Hui-Ting Chang, Shang-Tzen Chang * \\ School of Forestry and Resource Conservation, National Taiwan University, Taipei 106, Taiwan, ROC
}

Received 21 February 2005; received in revised form 31 May 2005; accepted 2 June 2005

Available online 20 July 2005

\begin{abstract}
China fir (Cunninghamia lanceolata var. lanceolata) and maple (Acer sp.) wood were etherified with isopropyl glycidyl ether and the decay resistance and light stability of the modified wood were assessed. CP/MAS ${ }^{13} \mathrm{C}$ NMR and FT-IR analyses indicated that new ether bonds containing isopropyl groups formed after reacting wood with isopropyl glycidyl ether. Modified wood samples were very resistant to decay when exposed to brown-rot fungus Laetiporus sulphureus or white-rot fungus Lenzites betulina for 60 days in the soil-block test. The isopropyl glycidyl ether treatment of wood was effective in decreasing formation of phenoxyl radicals upon UV irradiation and thus protecting wood from photodiscoloration.
\end{abstract}

(c) 2005 Elsevier Ltd. All rights reserved.

Keywords: Wood; Isopropyl glycidyl ether; CP/MAS ${ }^{13} \mathrm{C}$ NMR; FT-IR; ESR; Decay resistance; Light stability

\section{Introduction}

Wood, one of the lignocellulosic bioresource materials, is composed of mainly cellulose, hemicelluloses and lignin. These components are readily deteriorated by environmental factors such as light, water, temperature, and biological organisms (Chang et al., 1982; Feist et al., 1991; Pandey and Pitman, 2004). Many researches on chemical modifications have been concerned with improving dimensional stability and protecting wood from photodegradation and biological deterioration (Kumar, 1994; Kiguchi, 1997; Timar et al., 1999; Plackett et al., 1996; Norimoto, 2001). Typical modifications of wood are esterifications and etherifications at the hydroxyl groups of the cell wall. Wood may be esterified with such chemicals as anhydrides, ketene, acid chlorides, carboxylic acids, isocyanates. Wood esterified with different

\footnotetext{
* Corresponding author. Tel.: +8862 3366 4626; fax: +88622365 4520.

E-mail address: peter@ntu.edu.tw (S.-T. Chang).
}

types of anhydrides exhibited comparable dimensional stabilities, light fastness, and biological resistances (Matsuda, 1987; Chang and Chang, 2001, 2002). Among the various esterification treatments, acetylation was the most emphatic and extensive one in applications (Feist et al., 1991; Ohkoshi, 1996).

Wood also may be etherified with alkyl halogenides, epoxides, lactones, $\alpha, \beta$-unsaturated compounds, of which epoxides are the most often used. During etherification with epoxides, wood was reacted with propylene oxide or butylene oxide catalyzed with triethylamine, forming ether bonds with new hydroxyl groups of the cell wall components. Etherified wood was found to be resistant to attack by subterranean termites and rot fungi, and to be more dimensional stable (Rowell et al., 1976, 1979). Cetin and Hill (1999) investigated etherification of wood with epoxides, allyl glycidyl ether and glycidyl methacrylate and found that no reaction occurred between wood hydroxyl groups and the chemicals when pyridine was used as a solvent/catalyst. Therefore, choosing the catalyst was essential to the reaction between wood and epoxides. 
Recently more wood-esterifying chemicals have been explored and the influences on wood properties after etherification examined (Paulsson and Paraks, 2000; Evans et al., 2002). However, effect of etherification on wood properties has been much less reported than that for esterification. Therefore, we are interested in finding new etherifying chemicals for wood. In this study isopropyl glycidyl ether was used to etherify wood and fungal decay resistance, dimensional stability and light stability of modified wood were evaluated.

\section{Methods}

\subsection{Specimens}

China fir (Cunninghamia lanceolata var. lanceolata) and maple (Acer sp.) wood specimens were extracted with a solvent mixture of alcohol/ toluene $(1: 2, \mathrm{v} / \mathrm{v})$ for $24 \mathrm{~h}$, followed by leaching in running water for $12 \mathrm{~h}$ and then oven dried.

\subsection{Chemical modification of test specimens}

Wood specimens were vacuum immersed in neat isopropyl glycidyl ether (IGE) with 5\% triethylamine, as the catalyst, for $0.5 \mathrm{~h}$. The specimens in solution were then transferred to the glass reactors and were heated at $115{ }^{\circ} \mathrm{C}$ for various periods of time to achieve different weight gains (WGs). After reaction, the specimens were taken away from the solution and subjected to Soxhlet extraction with alcohol/toluene $(1: 2, \mathrm{v} / \mathrm{v})$ for $24 \mathrm{~h}$ to remove un-reacted chemicals and oven-dried at $105^{\circ} \mathrm{C}$ for $24 \mathrm{~h}$. The WG of specimens was calculated according to Eq. (1).

WG $(\%)=\left(W_{t}-W_{0}\right) / W_{0} \times 100$

where $W_{t}$ represents the oven-dried weight of chemically modified sample, $W_{0}$ represents the oven-dried weight of unmodified sample.

\section{3. $C P / M A S{ }^{13} C N M R$ spectra}

Solid State $\mathrm{CP} / \mathrm{MAS}{ }^{13} \mathrm{C}$ NMR spectra were obtained by the Bruker DMX-300 FT-NMR spectrometer, at the frequency of $75.47 \mathrm{MHz}$. Acquisition time was $0.035 \mathrm{~s}$. The relaxation delay was $7 \mathrm{~s}$ and the spectral width was $22,675 \mathrm{~Hz}$. Chemical shifts were calculated relative to TMS for spectrometer control. Wood powder was used for NMR analysis.

\subsection{FT-IR spectra}

The FT-IR spectra were obtained using a Bio-rad spectrometer FTS-40 incorporating a Spectra Tech diffuse reflectance accessory unit (DRIFT). Wood powder was used for FT-IR analysis. The spectral resolution was $4 \mathrm{~cm}^{-1}$ and the scanning wavenumber range was from 400 to $4000 \mathrm{~cm}^{-1}$.

\subsection{Decay tests}

Wood-rot fungi were purchased from Bioresource Collection and Research Center (BCRC, Taiwan). The resistance of modified specimens to decay by brown rot Laetiporus sulphureus (BCRC 35305) and white rot Lenzites betulina (BCRC 35296) were measured by the soilblock culture method, described in Chinese National Standard (CNS) 6717. Culture jars containing moist sea sand and $1 \mathrm{~cm}(L) \times 1 \mathrm{~cm}(T) \times 0.2 \mathrm{~cm}(R)$ wood feeder strips were sterilized at $121{ }^{\circ} \mathrm{C}$ for $30 \mathrm{~min}$, followed by inoculating the feeder strips (China fir and maple wood) with the basidiomycete test fungi. After sterilizing, the $2 \mathrm{~cm}$ by $2 \mathrm{~cm}$ by $2 \mathrm{~cm}$ test specimens were placed onto mycelium covered feeder strips and incubated at $26^{\circ} \mathrm{C}$ and $70 \%$ relative humidity for 60 days. After the test period, fungal mycelium on specimen surfaces was removed, and the specimens were dried at $105^{\circ} \mathrm{C}$ to constant weight. The weight loss for each individual sample was determined using Eq. (2). Triplicate specimens were tested for each treatment and the values were averaged.

Weight loss $(\%)=\left(W_{u}-W_{d}\right) / W_{u} \times 100$

where $W_{u}$ represents the oven-dried weight of sample prior to the decay test, $W_{d}$ represents the oven-dried weight of sample after the decay test.

\subsection{Bulking coefficient}

The bulking coefficient (BC) of wood after modification was calculated using the following Eq. (3) (Rowell and Ellis, 1978). Triplicate specimens were run and the values were averaged.

$\mathrm{BC}(\%)=\left(V_{t}-V_{u}\right) / V_{u} \times 100$

where $V_{t}$ and $V_{u}$ are the oven-dried volume of wood after and before modification, respectively.

\subsection{Antiswelling efficiency}

The size of specimen was $1 \mathrm{~cm}$ by $3 \mathrm{~cm}$ by $3 \mathrm{~cm}$ (longitudinal by radial by tangential). The antiswelling efficiency (ASE) was measured by the water-soaked method reported by Rowell and Ellis (1978). The volumetric swelling coefficient $(S)$ and the ASE were calculated according to their formulae. Triplicate specimens were run and the values were averaged.

\subsection{ESR analyses}

The electron spin resonance (ESR) spectra were obtained by Bruker EMX-10 spectrometer. The frequency 
of microwave is $9 \mathrm{GHz}$. The temperature of sample was set at $-196^{\circ} \mathrm{C}$. The power of mercury lamp was $200 \mathrm{~W}$. The size of wood powder was 60-80 mesh. Formations of phenoxyl radicals of wood powder (passed 60 mesh, $5 \mathrm{mg}$ ) under UV irradiation were measured at different irradiation times.

\subsection{Ultraviolet light irradiation}

The accelerated light fastness test of specimens measuring $3 \mathrm{~cm}$ by $3 \mathrm{~cm}$ by $1 \mathrm{~cm}$ (longitudinal by radial by tangential) was conducted in a Q-panel QUV weathering tester equipped with UVA-351 lamps. The temperature of the black panel was $60 \pm 2{ }^{\circ} \mathrm{C}$. Duplicate specimens were run in the light fastness test.

\subsection{Color measurements}

The changes of surface color of specimens were measured using a Jasco model 550 UV-VIS spectrophotometer equipped with an integrating sphere. Tristimulus values $X, Y$, and $Z$ of all the specimens were obtained from the spectral reflectance curve. According to the CIE $L^{*} a^{*} b^{*}$ system (Commission Internationale de l'Eclairage), yellowness index (YI) was computed.

\section{Results and discussion}

\subsection{Chemical structure changes of wood after modification}

The chemical changes of wood specimens treated with isopropyl glycidyl ether were examined by the solid state CP/MAS ${ }^{13} \mathrm{C}$ NMR and FT-IR spectroscopy. Fig. 1(b) and (d) show the ${ }^{13} \mathrm{C}$ NMR spectra of treated China fir (WG 25.7\%) and maple (WG 18.0\%) wood, respectively. The most obvious change was the appearance of a new absorption band at $22 \mathrm{ppm}$ of treated specimens arising from the methyl group $\left(\mathrm{CH}_{3}\right)$ (Kono et al., 1999), indicating the addition of isopropyl groups after the treatment. The relative intensity of absorption band at $60 \mathrm{ppm}$ (Fig. 1(b)), which has been assigned to the absorption of C-6 position in the amorphous region (Gilardi et al., 1995), decreased after the wood treated with isopropyl glycidyl ether, indicating that the etherification of cellulose occurred mainly at the C-6 position in the amorphous region. The decreased intensity at $73 \mathrm{ppm}$ indicated that the reaction also occurred at C2 or C-3 position of cellulose.

FT-IR spectra of treated China fir (WG 20.4\%) and maple (WG 12.8\%) wood are shown in Fig. 2(b) and (d), respectively. Significant changes in IR spectra were observed in both species after modification. An increase in the intensity of peak at $1165 \mathrm{~cm}^{-1}(\mathrm{C}-\mathrm{O}$ stretching) was detected in Fig. 2(b), indicating formation of ether bonds. The appearance of characteristic absorption bands of isopropyl groups at 1370 and $1379 \mathrm{~cm}^{-1}$ (gem-methyl $\mathrm{CH}_{3}$ bending) and $2965 \mathrm{~cm}^{-1}$ $\left(\mathrm{CH}_{3}\right.$ stretching) were also observed in the spectrum of treated specimens. The increased intensity at $1465 \mathrm{~cm}^{-1}\left(\mathrm{CH}_{2}\right.$ scissoring) band was attributable to an increase of methylene groups. No significant change in the intensity of the peak at $3400 \mathrm{~cm}^{-1}(\mathrm{O}-\mathrm{H}$ stretching) was observed because the new hydroxyl groups were also formed when wood was reacted with epoxides.

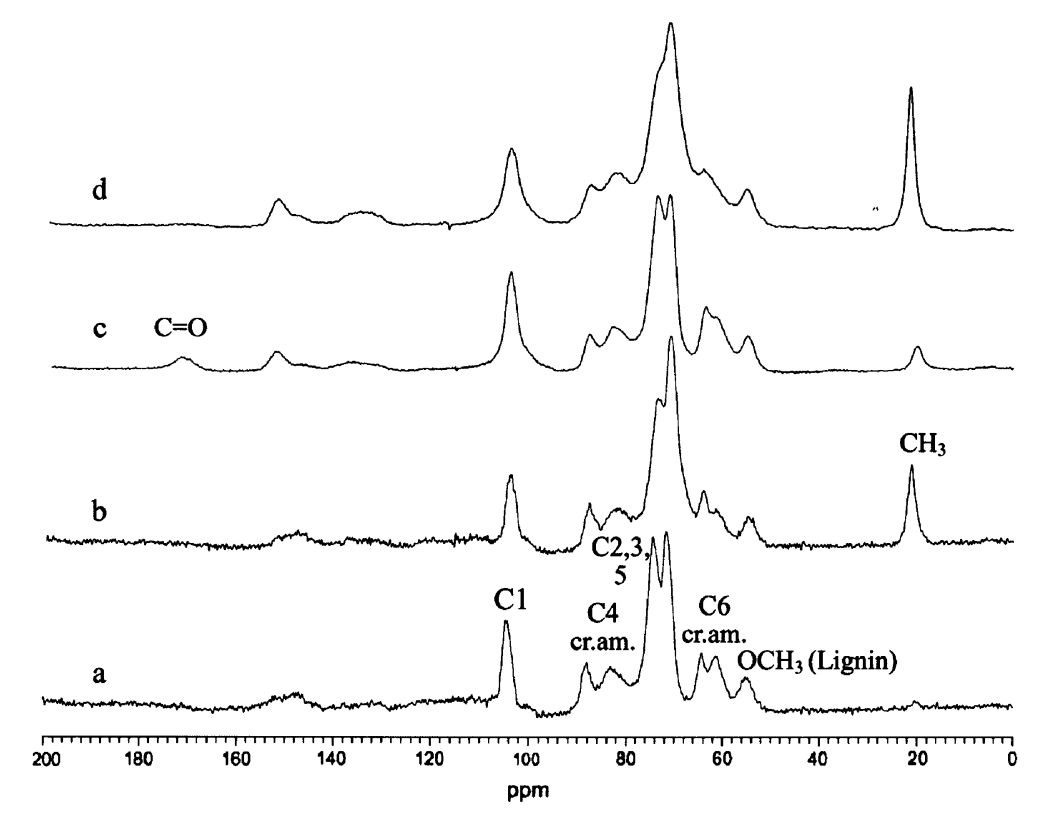

Fig. 1. CP/MAS ${ }^{13} \mathrm{C}$ NMR spectra of wood treated with isopropyl glycidyl ether. (a) China fir wood, control, (b) China fir wood, treated (WG $25.7 \%$ ), (c) maple wood, control, (d) maple wood, treated (WG $18.0 \%$ ). 


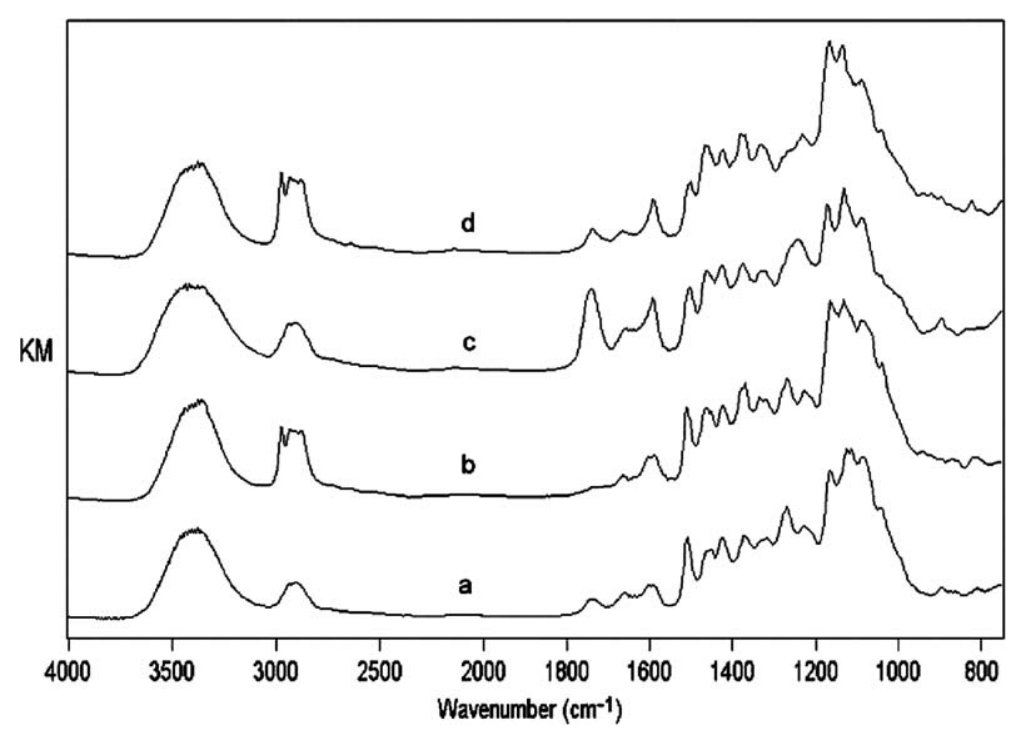

Fig. 2. FT-IR spectra of wood treated with isopropyl glycidyl ether. (a) China fir wood, control, (b) China fir wood, treated (WG 20.4\%), (c) maple wood, control, (d) maple wood, treated (WG 12.8\%).

In addition, $1736 \mathrm{~cm}^{-1}$ for $\mathrm{C}=\mathrm{O}$ in hemicelluloses or lignin of maple wood decreased after treatment (Fig. 2(d)), which is in agreement with the observation that the absorption band at $173 \mathrm{ppm}(\mathrm{C}=\mathrm{O})$ in ${ }^{13} \mathrm{C}$ NMR spectrum of treated maple wood was also absent (Fig. 1(d)). These results suggested the deacetylation of hemicelluloses or decarbonylation of lignin during the reaction. Extend of the decrement of carbonyl group absorption was more obvious in treated maple wood than that of treated China fir wood. The detailed reactions between wood and isopropyl glycidyl ether need further investigation.

Results from ${ }^{13} \mathrm{C}$ NMR and FT-IR spectral analyses confirmed the formation of ether bonds (Fig. 3) after treatment. Our results demonstrated that new ether bonds containing isopropyl groups formed after wood was reacted with isopropyl glycidyl ether when triethylamine was used as a catalyst. In contrast, with no reaction occurred between wood and allyl glycidyl ether or glycidyl methacrylate when pyridine was used as a solvent/catalyst (Cetin and Hill, 1999).

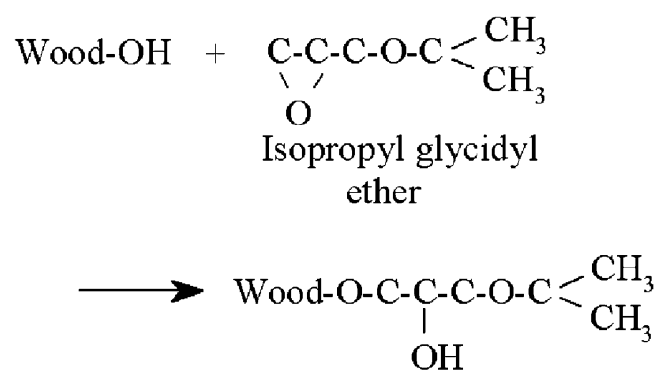

Fig. 3. Reaction for wood reacted with isopropyl glycidyl ether.

\subsection{Decay resistance of wood treated with isopropyl glycidyl ether}

Deterioration of wood by biological organisms is a serious problem in the use of wood products, and it is necessary to treat wood and wood products to prolong their service life. Fig. 4 shows the drastic reduction in weight loss of etherified wood due to fungal decay. After exposing to brown-rot fungus $L$. sulphureus for 60 days, weight loss of untreated China fir wood was $21.6 \%$, while the modified China fir wood (WG $12.2 \%$ ) only sustained a $0.73 \%$ weight loss. Decay resistance of China fir wood against the white-rot L. betulina was also greatly improved after etherification. Untreated maple wood samples sustained $24.94 \%$ and $18.99 \%$ weight loss, respectively, after exposing them to $L$. sulphureus and

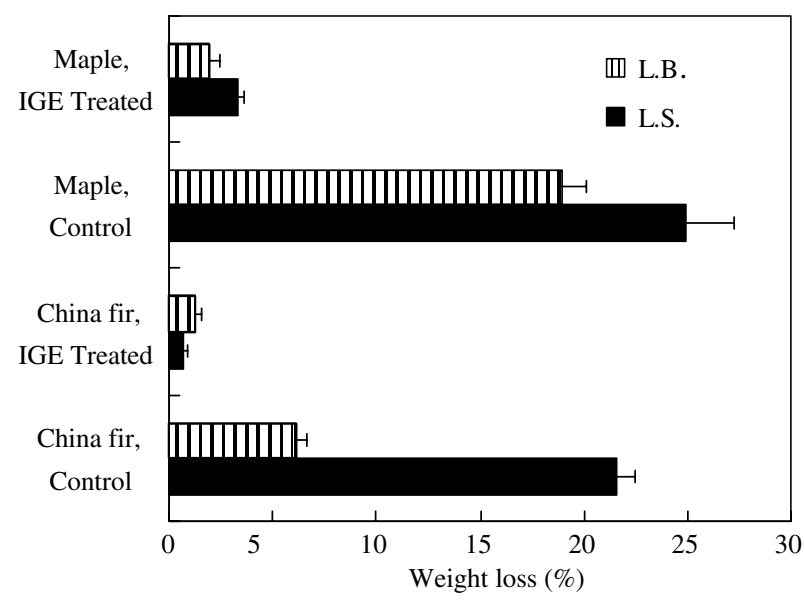

Fig. 4. Weight loss of etherified wood after decay test with brown-rot fungus $L$. sulphureus and white-rot fungus L. betulina for 60 days. 

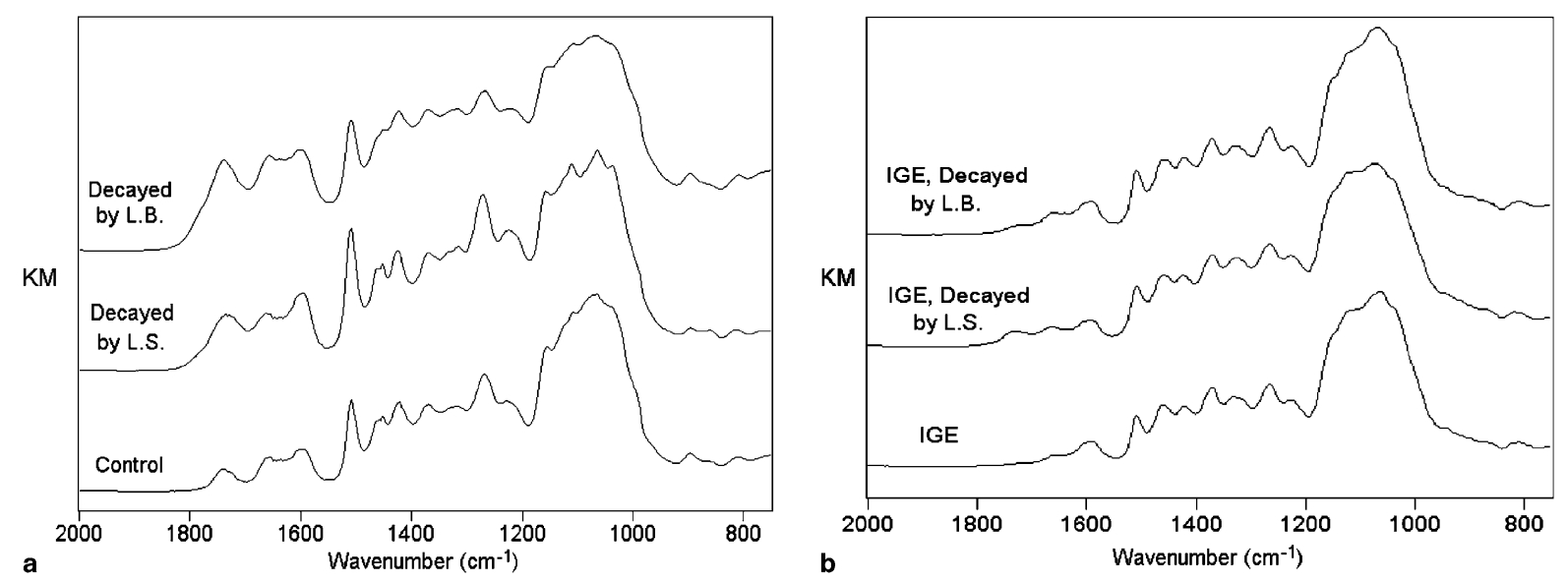

Fig. 5. FT-IR spectra of etherified China fir wood after wood-rot decay test for 60 days. (a) Control, (b) IGE treated (WG $12.2 \%$ ).

Table 1

Dimensional stability of China fir wood treated with isopropyl glycidyl ether after water-soaked test

\begin{tabular}{lrll}
\hline WG $(\%)$ & BC $(\%)$ & \multicolumn{2}{l}{ Water-soaked test } \\
\cline { 3 - 4 } & & \multicolumn{1}{l}{$S(\%)$} & ASE $(\%)$ \\
\hline Control & - & $14.1 \pm 0.4^{*}$ & - \\
12.1 & $5.6 \pm 0.4$ & $8.0 \pm 0.1$ & 43.2 \\
24.6 & $10.6 \pm 0.8$ & $5.7 \pm 0.1$ & 59.9 \\
\hline
\end{tabular}

* Average value \pm standard deviation.

L. betulina for 60 days. The corresponding weight losses of etherified maple wood were $3.31 \%$ and $1.97 \%$.

Changes in chemical structures of white- and brownrotted China fir wood also was analyzed by FT-IR spectroscopy. Brown-rot fungus $L$. sulphureus selectively consumed polysaccharides and left lignin behind, as indicated by the decrease in the $898 \mathrm{~cm}^{-1}$ band ( $\beta$-ano- meric deformation) intensity and significantly increased absorption at $1268 \mathrm{~cm}^{-1}$ (guaiacyl ring breathing) and $1510 \mathrm{~cm}^{-1}$ (aromatic skeletal vibration) (Fig. 5). The increased absorption intensity at $1735 \mathrm{~cm}^{-1}$ (carbonyl stretching) indicates oxidation of wood components during brown-rot decay. In the case of China fir wood, the intensity of lignin absorption bands at $1464 \mathrm{~cm}^{-1}$ (CH deformation) and $1510 \mathrm{~cm}^{-1}$ decreased after 60 days of white rot decay. Significant increased absorption at $1600 \mathrm{~cm}^{-1}$ (aromatic ring vibration plus carbonyl stretching), $1655 \mathrm{~cm}^{-1}$ (conjugated carbonyl stretching) and $1740 \mathrm{~cm}^{-1}$ may attribute to generation of carbonyl groups, such as ketone and carboxylic acid, as a result of white rot decay. Chemical changes in fungal decayed wood observed in this study are consistent with those reported in the literature (Pandey and Pitman, 2004; Ferraz et al., 2000; Moore and Owen, 2001).

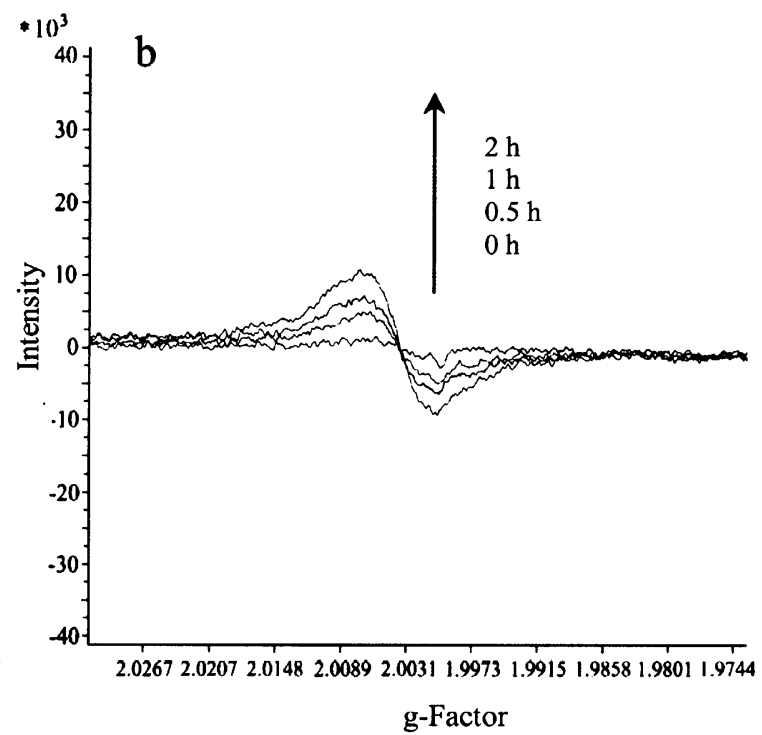

Fig. 6. ESR spectra of China fir wood treated with isopropyl glycidyl ether during UV irradiation. (a) Control, (b) treated (WG $24.5 \%$ ). 
Fig. 5(b) shows FT-IR spectra of etherified China fir wood exposed to decay fungi. There is little difference between the spectra of etherified wood before and after exposure to decay fungi for 60 days.

\subsection{Dimensional stability of wood treated with isopropyl glycidyl ether}

The dimensional stability of wood treated with isopropyl glycidyl ether is evaluated by the water-soaked method, and the antiswelling efficiencies of specimens are presented in Table 1 . The volumetric swelling coefficient of untreated China fir wood was $14.1 \%$. After modification, the volumetric swelling coefficient of etherified wood (WG $12.1 \%$ ) was reduced to $8.0 \%$, which is due to the volume increase after modification and consequently results in the decrease of the reversible swelling of wood in the water-soaked test. The antiswelling efficiency of etherified wood was $43.2 \%$. The antiswelling efficiency increased with increasing the WG of etherified wood, the antiswelling efficiency of specimen with higher WG $(24.6 \%)$ was $59.9 \%$. The improvement of antiswelling efficiency of wood treated with isopropyl glycidyl ether was as well as that of wood treated with alkylene oxide, such as propylene oxide or butylene oxide (Rowell et al., 1976). These results demonstrated that the dimensional stability of wood was greatly improved by isopropyl glycidyl ether treatment.

\subsection{Lightstability of wood treated with isopropyl glycidyl ether}

Fig. 6(a) shows ESR spectra of untreated China fir wood before and after exposure to UV irradiation.

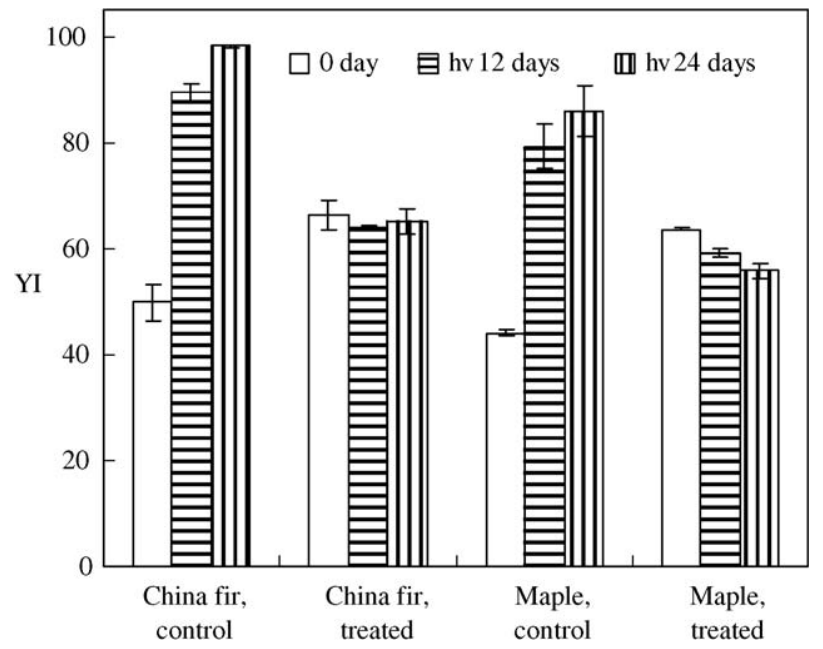

Fig. 7. Changes in yellowness index (YI) of etherified wood after UV light fastness test.

The ESR signal for phenoxyl radicals $(g \approx 2.003)$ during photolysis of wood continuously increased over time $(0-2 \mathrm{~h})$. These phenoxyl radicals would cause photodegradation and discoloration of wood (Heitner, 1993). Characteristics of ESR spectrum of untreated wood under UV irradiation observed in this study (Fig. 6(a)) were similar to those described in the previous paper (Cetin and Hill, 1999). The ESR spectra of etherified wood are shown in Fig. 6(b). Before UV irradiation, etherified wood contained much lower phenoxyl radicals concentration than the untreated sample. The signal for phenoxyl radicals of treated specimen also increased during UV irradiation, but the phenoxyl radical signals were approximately four-fold less than those of untreated sample. The ESR analysis shows clearly that
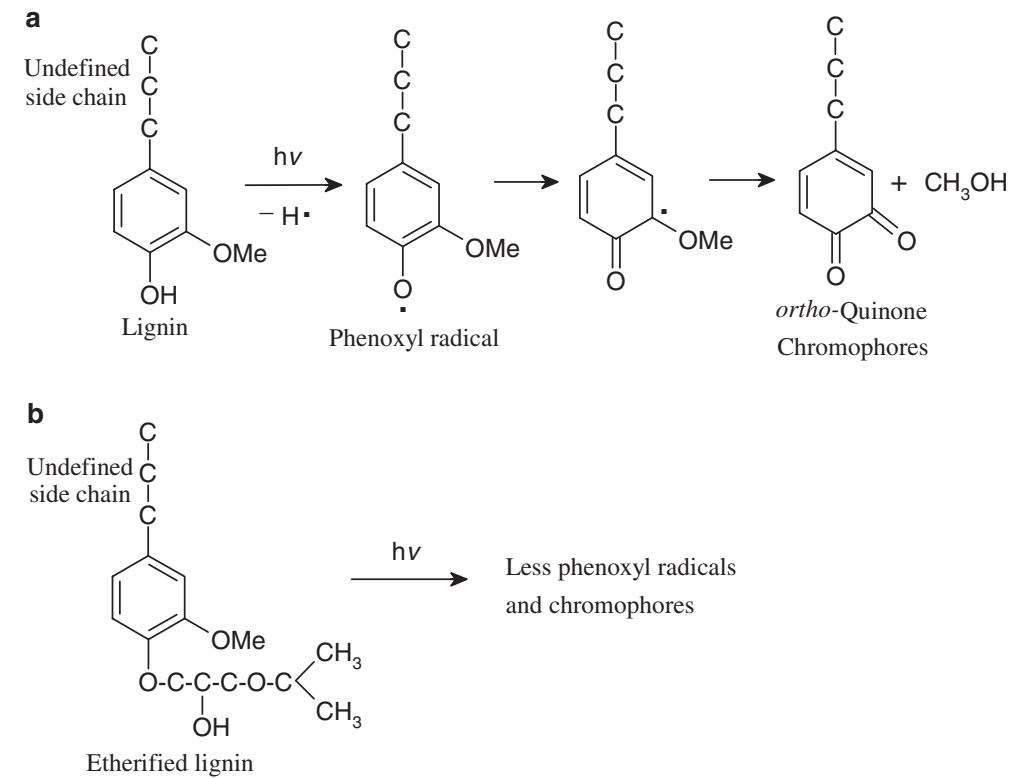

Fig. 8. Proposed mechanisms of lignin and etherified lignin during UV irradiation. (a) Control, (b) treated. 
etherification of wood inhibits generation of phenoxyl radicals during UV irradiation.

Changes in yellowness index (YI) of irradiated specimens after light fastness test are shown in Fig. 7. The YI of untreated China fir wood increased 48.3 units from 49.9 to 98.2 after 24 days UV irradiation, resulting in serious photoyellowing of wood surfaces. After 24 days UV irradiation, the YI of etherified China fir wood (WG $25.1 \%$ ) decreased 1.4 units from 66.4 to 65.0 , which was much lower than that of control (98.2). Although etherification of wood caused an increase of 16.6 YI units, further photoyellowing of etherified wood was effectively prevented during UV irradiation. Changes in YI of modified maple wood (WG 13.1\%) during UV irradiation were similar to those of etherified China fir wood, but a slight bleaching of sample surfaces was observed. Proposed mechanism for inhibiting the photoyellowing of etherified wood during UV irradiation is shown in Fig. 8.

\section{Conclusions}

${ }^{13} \mathrm{C}$ NMR and FT-IR spectral analyses of wood treated with isopropyl glycidyl ether indicated addition of isopropyl groups onto wood components through ether bonds. Etherified wood was found to be very resistant to brown-rot fungus L. sulphureus or the white-rot fungus $L$. betulina. Dimensional stability of wood was also improved by the isopropyl glycidyl ether modification. Results from the ESR analysis indicated that etherified wood inhibited the generation of phenoxyl radicals during UV irradiation and consequently lead to the decrease in the photoyellowing of treated wood.

\section{Acknowledgement}

The authors acknowledge the National Science Council of Taiwan for the financial support.

\section{References}

Chang, H.T., Chang, S.T., 2001. Inhibition of the photodiscoloration of wood by butyrylation. Holzforschung 55, 255-259.

Chang, H.T., Chang, S.T., 2002. Moisture excluding efficiency and dimensional stability of wood improved by acylation. Bioresour. Technol. 85, 201-204.

Chang, S.T., Hon, D.N.S., Feist, W.C., 1982. Photodegradation and photoprotection of wood surfaces. Wood Fiber 14, 104-117.

Cetin, N.S., Hill, C.A.S., 1999. An investigation of the reaction of epoxides with wood. J. Wood Chem. Technol. 19, 247-264.
Evans, P.D., Owen, N.L., Schmid, S., Webster, R.D., 2002. Weathering and photostability of benzoylated wood. Polym. Degrad. Stab. 76, 291-303.

Feist, W.C., Rowell, R.M., Ellis, W.D., 1991. Moisture sorption and accelerated weathering of acetylated and methylacrylated aspen. Wood Fiber Sci. 23, 128-136.

Ferraz, A., Baeza, J., Rodriguez, J., Freer, J., 2000. Estimating the chemical composition of biodegraded pine and eucalyptus wood by DRIFT spectroscopy and multivariate analysis. Bioresour. Technol. 74, 201-212.

Gilardi, G., Abis, L., Cass, A.E.G., 1995. Carbon-13 CP/MAS solidstate NMR and FT-IR spectroscopy of wood cell wall biodegradation. Enzyme Microb. Technol. 17, 268-275.

Heitner, C., 1993. Light-induced yellowing of wood-containing papers. In: Heitner, C., Scaiano, J.C. (Eds.), Photochemistry of Lignocellulosic Materials. American Chemical Society, Washington, DC, pp. 2-22.

Kiguchi, M., 1997. Photo-deterioration of chemically modified wood surfaces: acetylated wood and alkylated wood. Jpn. Agric. Res. Quart. 31, 147-154.

Kono, H., Numata, Y., Nagai, N., Erata, T., Takai, M., 1999. CPMAS ${ }^{13} \mathrm{C}$ NMR and X-ray studies of cellooligosaccharide acetates as a model for cellulose triacetate. J. Polym. Sci. Part A: Polym. Chem. 37, 4100-4107.

Kumar, S., 1994. Chemical modification of wood. Wood Fiber Sci. 26, 270-280.

Matsuda, H., 1987. Preparation and utilization of esterified woods bearing carboxyl groups. Wood Sci. Technol. 21, 75-88.

Moore, A.K., Owen, N.L., 2001. Infrared spectroscopic studies of solid wood. Appl. Spectrosc. Rev. 36, 65-86.

Norimoto, M., 2001. Chemical modification of wood. In: Hon, D.N.S., Shiraishi, N. (Eds.), Wood and Cellulosic Chemistry. Marcel Dekker, New York, pp. 573-598.

Ohkoshi, M., 1996. Light-induced color change of acetylated wood meal of kiri (Paulownia tomentosa Steud.). Mokuzai Gakkaishi 42, 216-221.

Pandey, K.K., Pitman, A., 2004. Examination of the lignin content in a softwood and a hardwood decayed by a brown-rot fungus with the acetyl bromide method and Fourier transform infrared spectroscopy. J. Polym. Sci. Part A: Polym. Chem. 42, 2340-2346.

Paulsson, M., Paraks, J., 2000. Chemical modification of chemithermomechanical pulps. Part 1: mechanical, optical, and aging properties of propionylated spruce CTMP. J. Wood Chem. Technol. 20, 205-224.

Plackett, D.V., Dunningham, E.A., Singh, A.P., 1996. Weathering of chemically modified wood. In: Hon, D.N.S. (Ed.), Chemical Modification of Lignocellulosic Materials. Marcel Dekker, New York, pp. 277-294.

Rowell, R.M., Ellis, W.D., 1978. Determination of dimensional stabilization of wood using the water-soaked method. Wood Sci. 13, 104-111.

Rowell, R.M., Gutzmer, D.I., Socks, I.B., Kinney, R.E., 1976. Effect of alkylene oxide treatment on dimensional stability of wood. Wood Sci. 9, 51-54.

Rowell, R.M., Hart, S.V., Esenther, G.R., 1979. Resistance of alkylene-oxide-modified southern pine to attack by subterranean termites. Wood Sci. 11, 271-274.

Timar, M.C., Pitman, A., Mihai, M.D., 1999. Biological resistance of chemically modified aspen composites. Int. Biodeterior. Biodegrad. 43, 181-187. 